\title{
Detection of SCC initiation in austenitic stainless steel by electrochemical noise measurements
}

\author{
Stefan Ritter* and Hans-Peter Seifert \\ Paul Scherrer Institut \\ Nuclear Energy and Safety Research Department \\ Laboratory for Nuclear Materials \\ 5232 Villigen PSI, SWITZERLAND \\ Phone: +41 56310 2983, Fax: +41 563102199 \\ E-mail: stefan.ritter@psi.ch
}

\begin{abstract}
The electrochemical noise (EN) measurement technique is one of the most promising tools for continuous in-situ corrosion monitoring in technical systems with a certain potential to be used for the detection of stress corrosion cracking (SCC). To evaluate the suitability of the EN technique for the detection of SCC initiation, a small but systematic test programme was started, performing EN measurements on type 304 austenitic stainless steel during constant extension rate tensile tests in aqueous thiosulphate solution at room temperature. SCC could be detected by EN measurements, which was verified by interruptions of the experiments at different stages, by testing steel with different degrees of sensitisation and by post-test fractography in the scanning electron microscope. Conclusions on the cracking mechanism could be drawn based on the current noise signal pattern.
\end{abstract}

Keywords: Electrochemical noise, stainless steel, stress corrosion cracking, corrosion monitoring, thiosulphate.

This document is the accepted manuscript version of the following article: Ritter, S., \& Seifert, H. P. (2013). Detection of SCC initiation in austenitic stainless steel by electrochemical noise measurements. Materials and corrosion, Werkstoffe und Korrosion, 64(8), 683-690. https://doi.org/10.1002/maco.201206700 


\section{Introduction}

Stress corrosion cracking (SCC) is one of the major degradation mechanisms that can affect the integrity of pipework and components in many industrial sectors. Even though a significant effort has been undertaken to study this phenomenon SCC remains difficult to manage in the field [1]. Especially SCC predicting capabilities, in particular with respect to the initiation process, are very limited. The early detection of the SCC initiation process by suitable component monitoring systems, and subsequent proper remedial actions, would significantly reduce the costs of damage, and help to prevent the occurrence of disastrous events.

Corrosion-resistant, austenitic stainless steels are widely used as construction material for pipings, vessels and other structural components, which enclose or come into contact with aggressive or mild environments and are subjected to relevant sustained mechanical loads. Intergranular (IG) SCC in these materials is therefore a common phenomenon, in particular, if the material is in a susceptible condition (e.g., sensitisation, cold-work, etc.). In the nuclear industry, IG SCC incidents have occurred in both boiling water and pressurised water reactors in a wide range of stainless steel and nickel-base alloy components such as reactor internals, (reactor) pressure vessel penetrations and nozzles, main coolant pipings and heat exchanger tubing [2, 3]. These SCC incidents have significantly affected plant availability/economics and in some cases have seriously compromised the integrity of the primary circuit, and thus safety. This clearly demonstrates the need for the development of advanced, non-destructive, continuous monitoring tools for the early detection of SCC initiation in the technical precrack stage.

In technical systems such as light water reactor facilities, the electrochemical noise (EN) measurement technique is one of the few promising corrosion monitoring tools for the early 
detection of SCC initiation [4-6], although no systematic investigations were performed so far in these high-temperature water environments. Most studies investigating the EN technique on its ability to detect SCC were performed in room temperature systems and had a rather “spot check” character [7-12], nevertheless revealing very valuable and promising results. Only very few attempts were made to investigate this technique in high-temperature water environments [13-17]. Therefore a test programme has been started at the Paul Scherrer Institute (PSI) to investigate the suitability of the EN technique for the detection of SCC initiation in high-temperature water systems (simulated boiling water reactor environment) [18]. To support these complex and time-consuming investigations in high-temperature water, a series of room temperature SCC tests with EN measurements were performed. In the current paper the results from the room temperature experiments are summarised.

\section{Material and experimental procedure}

\subsection{Investigated material and specimen}

A rod material of a high-carbon austenitic stainless steel AISI 304 was used for the SCC initiation tests, since this steel could be easily sensitised and showed a sufficiently high susceptibility to IG SCC (Tables 1 and 2). The material was used either in the solution annealed state with a very low degree of sensitisation (value from double-loop electrochemical potentiokinetic reactivation (DL-EPR) tests $<0.3 \%$; measured according to JIS G $0580_{1986}$ ) and therefore with a low susceptibility to IG SCC, or it was sensitised. The applied heat treatments at $620^{\circ} \mathrm{C}$ for 1,9 or $24 \mathrm{~h}$ resulted in high degrees of sensitisation (DL-EPR values $\approx 1,15$ and $28 \%$ ).

The tests were performed using round bar tensile specimens (Figure 1) with a U-shaped notch in the centre of the gauge section (gauge length $=36 \mathrm{~mm}$, diameter $=6 \mathrm{~mm}$, notch depth $=$ 
$0.2 \mathrm{~mm}$ ). The notch was used to restrict the SCC initiation to a small area of the specimen. The specimen was electrically insulated from the test facility.

\subsection{Experimental procedure}

The SCC initiation constant extension rate tensile (CERT) tests were performed in a water loop at room temperature and ambient pressure with an electromechanical tensile machine (Figure 2). $0.01 \mathrm{M} \mathrm{Na}_{2} \mathrm{~S}_{2} \mathrm{O}_{3}$ aqueous solution was pumped with a flow rate of ca. $1 \mathrm{l} / \mathrm{h}$ through a small test cell $\left(\mathrm{V}_{\text {cell }}=0.2 \mathrm{l}\right)$ mounted around the central section of a round bar tensile specimen (Figure 2a). The specimen was covered by shrinking tube, exposing only an area of about $60 \mathrm{~mm}^{2}$ around the notched section of the specimen to the electrolyte (Figure 2b). Specimen and test cell were shielded by a Faraday cage. After about three days at a preload of $1000 \mathrm{~N}$, the specimen was strained with a constant stroke rate of the pull-rod ( $\mathrm{v}_{\text {pull-rod}}$ ) of $7.2 \cdot 10^{-9} \mathrm{~m} / \mathrm{s}$, which corresponds to a nominal strain rate of $2 \cdot 10^{-7} \mathrm{~s}^{-1}$. A strain rate in the notch ground of the specimen of $6 \cdot 10^{-7} \mathrm{~s}^{-1}$ was estimated by Finite Element modelling. After the tests the specimens were carefully examined in the scanning electron microscope (SEM) and the in-depth cracking and fracture mode (IG or transgranular (TG) SCC, ductile mechanical failure, etc.) were investigated after opening the specimen by mechanical overloading in air at room temperature.

\subsection{Electrochemical noise measurements}

The electrochemical potential (EPN) and current noise (ECN) were recorded either by a GAMRY $^{\mathrm{TM}}$ potentiostat (ESA400 software) with a sampling rate of $5 \mathrm{~Hz}$ or by a newly developed EN measurement device (EcmNoise, IPS Germany) with a sampling rate of $4 \mathrm{~Hz}$. In both cases the signals were treated with low-pass filters to avoid aliasing. The EN measurement devices were qualified and characterised by “round-robin” testing (within the European Cooperative Group on Corrosion Monitoring of Nuclear Materials - ECG-COMON 
[19]) and by dummy cell testing according to a guideline for an assessment of EN measurement devices [20]. The ECN was recorded with a zero resistance ammeter between a C-ring (surface $\approx 230 \mathrm{~mm}^{2}$ ), made out of the same steel (solution annealed) as the specimen, and the round bar tensile specimen (Figure 2a). The EPN of specimen and C-ring was measured versus a Pt-wire (pseudo reference electrode) which was aligned around the Unotch of the specimen (Figure 2b). For comparison reasons an offset correction of the EPN and ECN signals was performed during the evaluation process of the noise data in a way that the potential and current baseline level were zero when the loading phase started $(\mathrm{t}=0 \mathrm{~h})$. The course of the signals was not modified. In the current paper only evaluation in the timedomain is presented, as the transformation of the EN data into the frequency-domain (calculating power spectra by Fast Fourier Transformation) revealed no additional insights (so far). Power spectra were mainly used to identify disturbances in the EN signal. 


\section{Results and discussion}

\subsection{Characteristic noise pattern during SCC initiation and growth}

A series of 12 CERT tests with stainless steels of different degrees of sensitisation with simultaneous ECN and EPN measurements were performed in aqueous thiosulphate solution. Figure 3 shows the typical course of the ECN and EPN signals during a CERT test with a heavily sensitised stainless steel. In this case the specimen was strained until severe SCC was expected, then it was unloaded to the small pre-load and finally the test was finished. Post-test fractography by SEM confirmed that IG SCC occurred in the notched area of the specimen (Figure 4). As can be seen from the EPN signal of the initial phase of the first test shown in Figure 3a, some fluctuations of the signal were observed which were not related to cracking. It is believed that these fluctuations were caused by small changes of the temperature and $\mathrm{pH}$ value of the solution. After a further optimisation of the test setup these fluctuations could be reduced remarkably in the following tests. The ECN signal was always very "quiet” and stable before and during the specimen was loaded (before cracking started). Around the time when the nominal yield strength was reached, current and potential transients in positive and negative direction of increasing magnitude and frequency were usually observed (Figure 3b). In all EN measurements the polarity of the current was selected in a way that a positive current corresponds to anodic reactions on the specimen. The single current peaks during the initial phase of SCC initiation consisted of a sudden rise (very few seconds) and a somewhat slower drop of the current to the initial signal level in the range of five seconds to few minutes, depending on the initial height of the transient. In Figure 5 a typical example of a single transient is shown. It can be seen that most of the current transients did not show a continuous decay of the current, but a small step towards the final phase of the transient. The potential transients revealed a slightly different shape. The potential decreased rather fast until the little step in the current signal (Figure 5) and then recovered rather slowly (some few 
minutes to about 20 minutes). After a while the baseline of the ECN and EPN signals started to increase and decrease, respectively. After unloading of the specimen, before complete failure, the transients disappeared and the signals returned slowly back to their original levels.

\subsection{Interpretation by the slip-dissolution mechanism}

The transients in the noise signals, respectively the steep increase of the current, can be explained by rupture of the protective passive film on the stainless steel due to, e.g., dynamic plastic strain at the surface or crack-tip and subsequent anodic metal dissolution. This crack initiation process is then slowed down by repassivation, causing the (slower) decrease of the current. As soon as the crack tip and walls are fully repassivated, the metal dissolution is extremely limited and the current drops to its initial value. Accordingly the potential decreases steeply during crack initiation events and starts increasing after the crack repassivated. Due to the double-layer capacity at the steel-electrolyte interface it takes much longer for the EPN values to reach the original level. This whole process is schematically described in Figure 6. With further increasing strain the baseline ECN signal increased and the baseline EPN signal decreased. This can be explained by the superposition of many transients caused by simultaneous multiple initiation of several cracks or fast continuous crack growth. These observations are in agreement with the slip-dissolution mechanism (Figure 6), which is explained in more detail in [21, 22]. A similar behaviour and interpretation of the noise signal was reported by Aballe et al. [11] and Watanabe et al. [12].

\subsection{Verification of the results by systematic CERT testing}

In the framework of the current project it was not possible to verify the results described above with a second, independent corrosion monitoring method. Therefore, further systematic testing was performed instead. Additional CERT tests with specimens of different degrees of sensitisation and control tests with solution annealed stainless steel were conducted. Some 
tests were finished after the first appearance of relevant current and potential transients and the specimens were investigated very carefully in the SEM after these tests.

In Figure 7 the ECN and EPN signals of a test are shown, which was finished shortly after two small and one larger transients, consisting of a number of overlapping transients, appeared. Careful post-test examination of the specimen in the SEM showed one crack with a surface crack length of about $0.7 \mathrm{~mm}$ and depth of about $0.3 \mathrm{~mm}$ (Figure 8). Another test was interrupted after four small transients, revealing four small IG SCC cracks. Finally a test with a less sensitised stainless steel (“G”) was finished right after a single, very small current and potential transient of only about $20 \mathrm{nA}$ and $5 \mathrm{mV}$, respectively (Figure 9). Fractographically only one very small crack with a surface crack length of about $0.07 \mathrm{~mm}$ and depth of about $0.04 \mathrm{~mm}$ could be discovered (Figure 10). These observations confirmed quite well that a correlation between ECN/EPN signal and cracking seems reasonable and demonstrated that the detection of a single SCC initiation site with a crack size of about 0.07 times $0.04 \mathrm{~mm}$ by EN measurements is possible, at least under lab conditions in the current corrosion system. Nevertheless the test programme was continued to gather additional confirmation of the ability of the EN technique to detect SCC initiation.

The results of a CERT test with a very slightly sensitised material ("F”) can be seen in Figure 11. Here small transients and an increase/decrease of the baseline current and potential signals were observed at very high stress levels significantly above the nominal yield stress, close to elongation at fracture (corresponding to a very high plastic strain at the notch root) and therefore much later than in tests with heavily sensitised steel. This is plausible, as cracking is expected to occur at higher stresses and mostly in a TG mode. Post-test analysis in the SEM revealed a large number of TG cracks, whereas no IG cracking could be resolved. From this test it might also be concluded that TG cracking can be also be detected by EN, although the 
noise pattern is somewhat different from IG SCC (e.g., smaller number of individual transients).

To further verify if the characteristic noise pattern (described above) can be attributed to SCC initiation and (early) crack growth, two control tests with solution annealed stainless steel (“C”) were performed. The specimens were unloaded just after exceeding the nominal yield strength, where SCC was usually observed in the experiments with sensitised steel, but not (yet) with the less SCC susceptible solution annealed steel. As expected, neither transients (Figure 12a) nor cracks (by SEM investigation) could be indentified. Only a very minor increase/decrease of the baseline current/potential signal appeared (Figure 12b), which was probably caused by the plastic deformation of the specimen and the generation of slip steps with immediate repassivation without crack initiation.

\subsection{Correlation of measured charge and dissolved metal}

In the sub-chapters above it was stated, that the current transients are caused by anodic metal dissolution along Cr depleted grain boundaries during the SCC process (slip-dissolution mechanism). Therefore, according to Faraday`s Law, the charge accumulated as ECN during the test should be proportional to the amount of dissolved metal. To verify this, the charge of some tests was calculated by integrating the respective ECN curve over the time (see example in Figure 13). From this charge value the volume of dissolved metal could be calculated by Equation 1. As the crack flank surface could be estimated from the detailed fractographical SEM investigations, the width of the dissolved metal along the crack (which does not correspond to the total crack opening) could be calculated (Equation 2). For the calculations some basic assumptions have been made: dissolved metal = Fe; charge number $=2$; a baseline offset correction of the current was applied before integration, setting the passive current as lower limit; width of dissolved metal = constant over the whole cracked area. Furthermore, it 
has to be considered that, according to Sarmiento Klapper et al. [23, 24], the cathodic process and the corresponding electron consumption may reduce the amplitude of the ECN signal. On the other hand it is believed that in the investigated corrosion system this effect is rather small, as the cathodic process is expected to be inhibited, respectively delayed because of the stable passive layer on the stainless steel surface.

$$
V_{\text {crack }}=\frac{M}{\rho \cdot z \cdot F} \cdot I \cdot t
$$

$V=$ volume of dissolved metal $(\mathrm{Fe}), \mathrm{M}=$ atomic weight of $\mathrm{Fe}$, density of $\mathrm{Fe}, \mathrm{z}=$ charge number, $F=$ Faraday`s constant, $I=$ current, $t=$ time.

$$
b_{\text {crack }}=\frac{V_{\text {crack }}}{A_{\text {crack }}}
$$

$b=$ width of dissolved metal, $V=$ crack (dissolved metal) volume, $A=$ crack flank surface.

Unfortunately only four tests could be evaluated in this way, because the crack flank area could not be estimated precisely enough in the other experiments. In spite of this and of the basic assumptions made, some reasonable results were obtained, which are summarised in Table 3. Test 1 , with a rather large crack and corresponding charge, revealed a dissolved metal width along the crack of $79 \mathrm{~nm}$. Assuming a small reduction of the charge and therefore slightly lower dissolved crack width value due to the electron consuming cathodic process (see above and [23, 24]), this crack width value is exactly in the expected range where the Cr content along grain boundaries of a heavily sensitised stainless steel falls below the critical value of 12 wt.\% [7, 25, 26], which facilitates metal dissolution. The calculated dissolved metal width of tests 2 and 3 with much smaller cracks are in a very similar range (78 and $83 \mathrm{~nm})$. From test 4, a crack width of only $47 \mathrm{~nm}$ was calculated, which can be explained very well by the lower degree of sensitisation, respectively smaller area of grain boundary Cr 
depletion, in comparison to the heavily sensitised steel used in the first three experiments. For the heavily sensitised material a charge per crack flank surface of about $2.2 \mathrm{mC} / \mathrm{mm}^{2}$ was obtained. A SCC study by sophisticated microcapillary measurements with exactly the same steel but different electrolyte revealed very similar values for the charge per crack flank surface and for the width of dissolved metal [27], further confirming the current results.

\subsection{Assessment of the EN technique as SCC initiation monitoring tool}

The results from Chapter 3.4, together with the observations described in the previous subchapters and the few comparable investigations from literature [7, 10-13] clearly demonstrate that detection of SCC initiation in stainless steel in highly conductive, aqueous solution at room temperature by the EN technique is possible, at least on the lab scale. E.g., if the DC part of the current/potential signal is removed by high-pass filtering (see an example in Figure 14) and/or the standard deviation of the ECN or EPN signals is calculated "online”, a robust and reliable corrosion monitoring tool for lab investigations of SCC initiation is available with the EN technique. Nevertheless further systematic investigations with a second independent corrosion monitoring technique would be extremely valuable to confirm these results, to optimise the measurement setup and to finally apply the EN technique as a SCC monitoring tool in the industrial field. Some very promising results combining different monitoring techniques were recently published by Kovač et al. [28, 29]. At PSI the experience gained during the presented study, was already successfully "transferred” to high-temperature water systems and used for EN measurements detecting SCC in stainless and low-alloy steel in simulated boiling water reactor environment (e.g., see [18, 30]). 


\section{Summary and conclusions}

The EN technique has been evaluated on it suitability for the detection of SCC initiation in austenitic stainless steel. A series of CERT tests with a type 304 stainless steel in aqueous thiosulphate solution at room temperature with simultaneous measurements of ECN and EPN were performed. Characteristic noise patterns could be identified which were attributed to crack initiation. Current transients in positive direction and potential transients with negative polarity were interpreted as crack initiation events according to the slip-dissolution model. Interruption of SCC testing at different stages and testing of stainless steels with different degrees of sensitisation, as well as careful post-test fractography in the SEM delivered clear evidence that the characteristic EN patterns are related to SCC initiation. Based on these results and on further evaluation of the ECN data, which related the measured charge to the crack sizes, respectively dissolved metal, it was concluded that the EN technique could be used as a reliable corrosion monitoring tool for the detection of SCC initiation, at least in the lab and in comparable corrosion systems.

For the future, further research is needed to confirm these results and to transfer this technique to other corrosion systems and finally to industrial applications.

\section{Acknowledgements}

The results of this paper were generated within the KORA research programme. The financial support of the programme by the Swiss Federal Nuclear Safety Inspectorate (ENSI) is gratefully acknowledged. Thanks are also expressed to B. Baumgartner, L. Nue, U. Tschanz

and B. Gerodetti (all PSI) for their experimental contribution to this work and to K. Reichlin (PSI) for the Finite Element calculations. 


\section{References}

[1] R.H. Jones and R.E. Ricker, "Mechanisms of Stress Corrosion Cracking", in: Stress Corrosion Cracking - Materials Performance and Evaluation, Ed.: R.H. Jones, ASM International: Materials Park, Ohio, USA, 1992, pp. 1-40.

[2] R. Kilian and A. Roth, Mater. Corros. 2002, 53, 727.

[3] P. Scott, "An Overview of Materials Degradation by Stress Corrosion Cracking in PWRs", in: EUROCORR 2004, EFC, Paper No. 563, Nice, France, September 12-16, 2004.

[4] R.A. Cottis, Corrosion 2001, 57(3), 265.

[5] J. Göllner, Mater. Corros. 2004, 55(10), 727.

[6] S. Ritter, D.A. Horner, and R.-W. Bosch, Corros. Eng. Sci Techn. 2012, 47(4), 251.

[7] D.B. Wells, J. Stewart, R. Davidson, P.M. Scott, and D.E. Williams, Corros. Sci. 1992, 33(1), 39.

[8] J.L. Dawson, "Electrochemical Noise Measurement: The Definitive in-Situ Technique for Corrosion Applications?" in: Electrochemical Noise Measurement for Corrosion Applications, ASTM, American Society for Testing and Materials, Montreal, Quebec, Canada, May 16-17, 1994.

[9] D.A. Eden, "Electrochemical Noise - the First Two Octaves", in: NACE Corrosion, NACE, Paper No. 386, San Diego, CA, USA, March 22-27, 1998.

[10] M. Leban, A. Legat, and V. Dolecek, "Detection and Differentation of SCC Processes", in: NACE Corrosion, NACE, Paper No. 02438, Denver, CO, USA, April 7-11, 2002.

[11] A. Aballe, R.C. Newman, and R.A. Cottis, "Electrochemical Noise Study of Stress Corrosion Cracking of Sensitized 304H in Thiosulfate", in: NACE Corrosion, NACE, Paper No. 03403, San Diego, CA, USA, 2003.

[12] Y. Watanabe and T. Kondo, Corrosion 2000, 56(12), 1250.

[13] J. Stewart, D.B. Wells, P.M. Scott, and D.E. Williams, Corros. Sci. 1992, 33(1), 73.

[14] S. Ritter, A. Molander (Eds.), "Corrosion Monitoring in Nuclear Systems - Research and Applications", EFC Publications, Vol. No. 56, Maney Publishing: London, UK, 2010.

[15] J. Göllner, A. Burkert, P. Deimel, and K. Klenke, Mater. Corros. 1998, 49(9), 671.

[16] J. Hickling, D.F. Taylor, and P.L. Andresen, Mater. Corros. 1998, 49(9), 651.

[17] Y. Watanabe, T. Shoji, and T. Kondo, "Electrochemical Noise Characteristics of IGSCC in Stainless Steels in Pressurized High-Temperature Water", in: NACE Corrosion, NACE, Paper No. 129, San Diego, CA, USA, March 22-27, 1998.

[18] S. Ritter and H.P. Seifert, "Detection of Stress Corrosion Cracking in a Simulated BWR Environment by Combined Electrochemical Potential Noise and Direct Current Potential Drop Measurements", in: Corrosion Monitoring in Nuclear Systems: Research and Applications, Eds.: S. Ritter and A. Molander, EFC Publications, No. 56, Maney Publishing: London, UK, ISBN 978-1-906540-98-2, pp. 46-62, 2010. 
[19] Website of the European Cooperative Group on Corrosion Monitoring of Nuclear Materials - ECG-COMON, available from: http://www.ecg-comon.org (viewed on May 1, 2012).

[20] S. Ritter, F. Huet, and R.A. Cottis, Mater. Corros. 2012, 63(4), 297.

[21] P.L. Andresen and F.P. Ford, "Modeling and Life Prediction of Stress Corrosion Cracking in Sensitized Stainless Steel in High Temperature Water", in: Predictive Capabilities in Environmentally Assisted Cracking, Ed.: R. Rugta, ASME: New York, USA, p. 17-39, 1985.

[22] R.C. Newman and C. Healey, Corros. Sci. 2007, 49(10), 4040.

[23] H. Sarmiento Klapper, J. Goellner, and A. Heyn, Corros. Sci. 2010, 52(4), 1362.

[24] H. Sarmiento Klapper, J. Göllner, A. Heyn, and A. Burkert, Mater. Corros. 2012, 63(1), 54.

[25] E.P. Butler and M.G. Burke, Acta Metall. 1986, 34(3), 557.

[26] R.C. Newman and K. Sieradzki, Corros. Sci. 1983, 23(4), 363.

[27] M. Breimesser, S. Ritter, H.P. Seifert, S. Virtanen, and T. Suter, Corros. Sci. 2012, 55, 126.

[28] J. Kovač, C. Alaux, T.J. Marrow, E. Govekar, and A. Legat, Corros. Sci. 2010, 52(6), 2015.

[29] J. Kovač, T.J. Marrow, E. Govekar, and A. Legat, Mater. Corros. 2012, DOI: 10.1002/maco.201106182 (to appear).

[30] S. Ritter and H.P. Seifert, "Environmentally-Assisted Crack Initiation Behaviour of Low-Alloy Steel in Simulated BWR Environment - Effect of Chloride", in: $18^{\text {th }}$ International Corrosion Congress, ICC, Paper No. 429, Perth, Australia, November 20 24, 2011. 


\section{Tables}

Table 1: Chemical composition of the investigated material in wt.\%.

\begin{tabular}{cccccccccccccc}
\hline AlSI & Design. & $\mathrm{C}$ & $\mathrm{Si}$ & $\mathrm{Mn}$ & $\mathrm{P}$ & $\mathrm{S}$ & $\mathrm{Cr}$ & $\mathrm{Mo}$ & $\mathrm{Ni}$ & $\mathrm{Co}$ & $\mathrm{Cu}$ & $\mathrm{Nb}$ & $\mathrm{Ti}$ \\
\hline \multirow{2}{*}{304} & $\begin{array}{l}\text { C, F, } \\
\text { G, D }\end{array}$ & 0.062 & 0.15 & 0.53 & 0.023 & 0.029 & 18.3 & 0.273 & 8.59 & 0.169 & 0.296 & 0.019 & 0.001 \\
\hline
\end{tabular}

Table 2: Mechanical properties and heat treatments of the investigated material (WQ = water quenched, YS = yield strength, UTS = ultimate tensile strength).

\begin{tabular}{ccccccccc}
\hline AISI & Design. & Type & $\begin{array}{c}\text { Product } \\
\text { form }\end{array}$ & $\begin{array}{c}\text { YSair } 25^{\circ} \mathrm{C} \\
{[\mathrm{MPa}]}\end{array}$ & $\begin{array}{c}\text { UTS } \mathrm{air}^{25^{\circ} \mathrm{C}} \\
{[\mathrm{MP} \text { ] }}\end{array}$ & $\begin{array}{c}\text { Solution annealing } \\
\text { heat treatment }\end{array}$ & $\begin{array}{c}\text { Sensitisation } \\
\text { heat treatment }\end{array}$ & $\begin{array}{c}\text { DL-EPR } \\
\text { value }\end{array}$ \\
\hline 304 & $\mathrm{C}$ & $\begin{array}{c}\text { High- } \\
\text { carbon }\end{array}$ & Rod & 291 & 686 & $1050^{\circ} \mathrm{C} / 30 \mathrm{~min} / \mathrm{WQ}$ & - & $<0.3 \%$ \\
304 & $\mathrm{~F}$ & $\begin{array}{c}\text { High- } \\
\text { carbon }\end{array}$ & Rod & - & - & $1050^{\circ} \mathrm{C} / 30 \mathrm{~min} / \mathrm{WQ}$ & $620^{\circ} \mathrm{C} / 1 \mathrm{~h} / \mathrm{WQ}$ & $\approx 1 \%$ \\
304 & $\mathrm{G}$ & $\begin{array}{c}\text { High- } \\
\text { carbon }\end{array}$ & Rod & - & - & $1050^{\circ} \mathrm{C} / 30 \mathrm{~min} / \mathrm{WQ}$ & $620^{\circ} \mathrm{C} / 9 \mathrm{~h} / \mathrm{WQ}$ & $\approx 15 \%$ \\
304 & $\mathrm{D}$ & $\begin{array}{c}\text { High- } \\
\text { carbon }\end{array}$ & Rod & - & - & $1050^{\circ} \mathrm{C} / 30 \mathrm{~min} / \mathrm{WQ}$ & $620^{\circ} \mathrm{C} / 24 \mathrm{~h} / \mathrm{WQ}$ & $\approx 28 \%$ \\
\hline
\end{tabular}

Table 3: Summary of the charge (Q), crack flank surface (A), crack (dissolved metal) volume

(V) and crack (dissolved metal) width (b) measured and calculated from four experiments.

\begin{tabular}{lccccccc}
\hline \multicolumn{1}{c}{ Test number } & Material & $\begin{array}{c}\text { DL-EPR } \\
\text { value }\end{array}$ & $\begin{array}{c}Q_{E C N} \\
{[\mathrm{C}]}\end{array}$ & $\begin{array}{c}A_{\text {crack }} \\
{\left[\mathrm{mm}^{2}\right]}\end{array}$ & $\begin{array}{c}Q_{E C N} / A_{\text {crack }} \\
{\left[\mathrm{mC}^{2} \mathrm{~mm}^{2}\right]}\end{array}$ & $V_{\text {crack }}\left[\mathrm{mm}^{3}\right]$ & $\begin{array}{c}\text { b crack } \\
{[\mathrm{nm}]}\end{array}$ \\
\hline 1 (Figure 3) & $\mathrm{D}$ & $\approx 28 \%$ & $2.95 \cdot 10^{-2}$ & 13.6 & 2.17 & $1.08 \cdot 10^{-3}$ & 79 \\
2 (Figure 7) & $\mathrm{D}$ & $\approx 28 \%$ & $3.82 \cdot 10^{-4}$ & 0.18 & 2.12 & $1.40 \cdot 10^{-5}$ & 78 \\
3 (not shown) & $\mathrm{D}$ & $\approx 28 \%$ & $1.74 \cdot 10^{-5}$ & 0.008 & 2.18 & $6.37 \cdot 10^{-7}$ & 83 \\
4 (Figure 9) & $\mathrm{G}$ & $\approx 15 \%$ & $3.85 \cdot 10^{-6}$ & 0.003 & 1.28 & $1.41 \cdot 10^{-7}$ & 47 \\
\hline
\end{tabular}




\section{Figures}

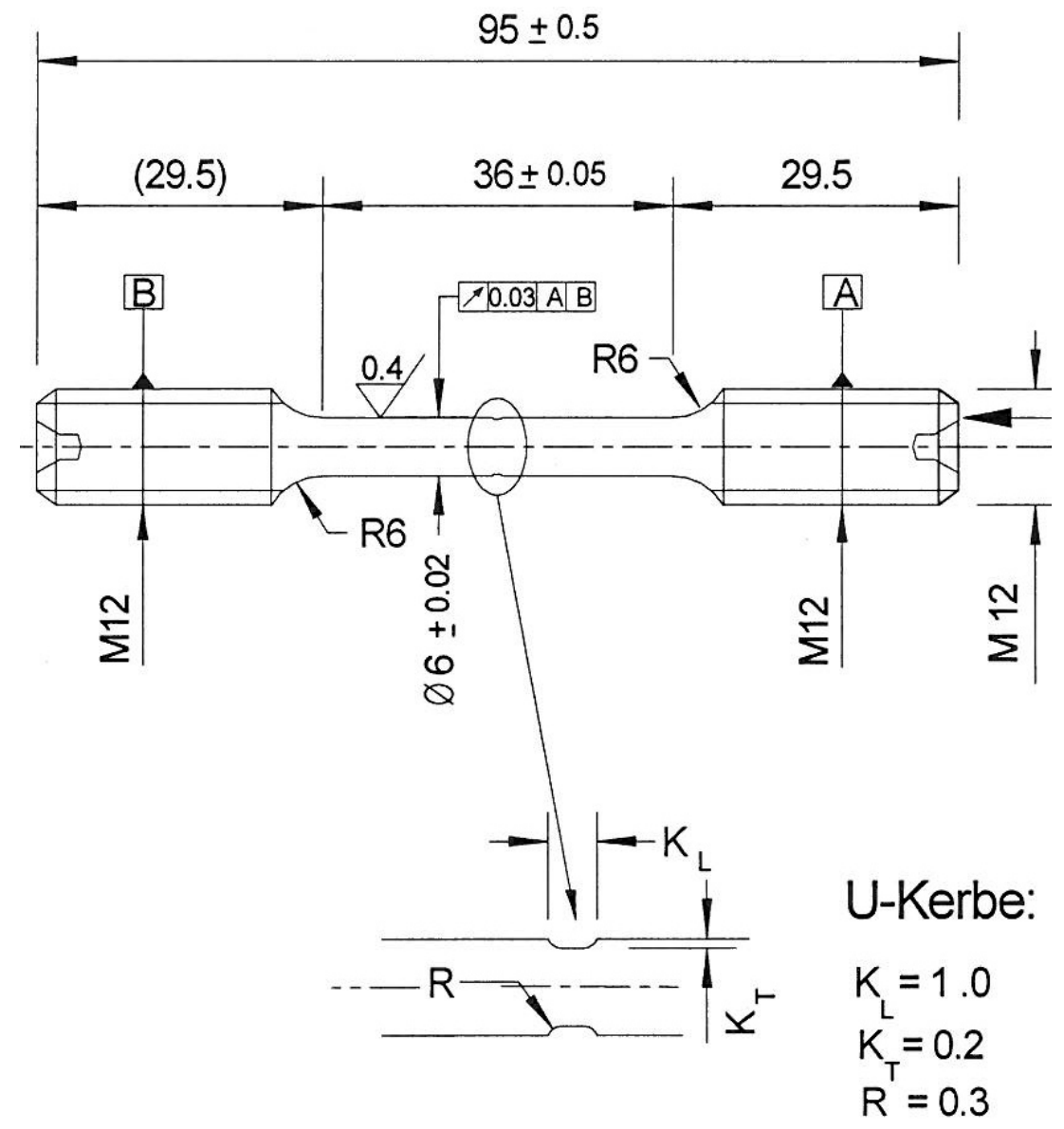

Figure 1: Schematic of the round bar specimen with U-shaped notch (dimensions in mm). 
a)

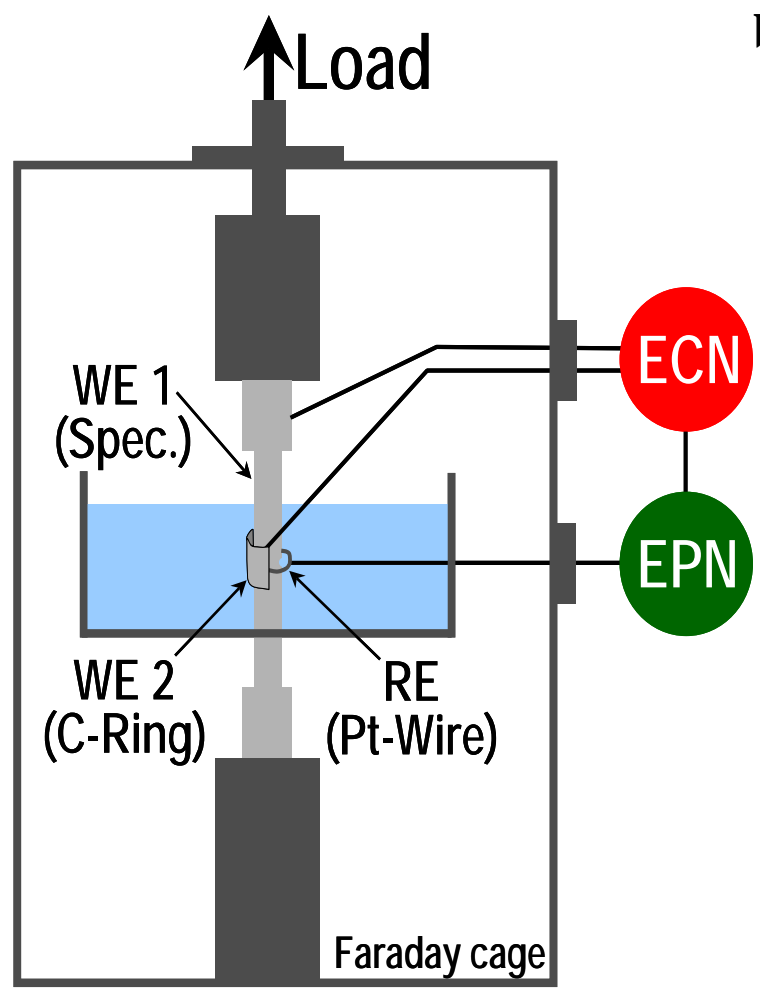

b)
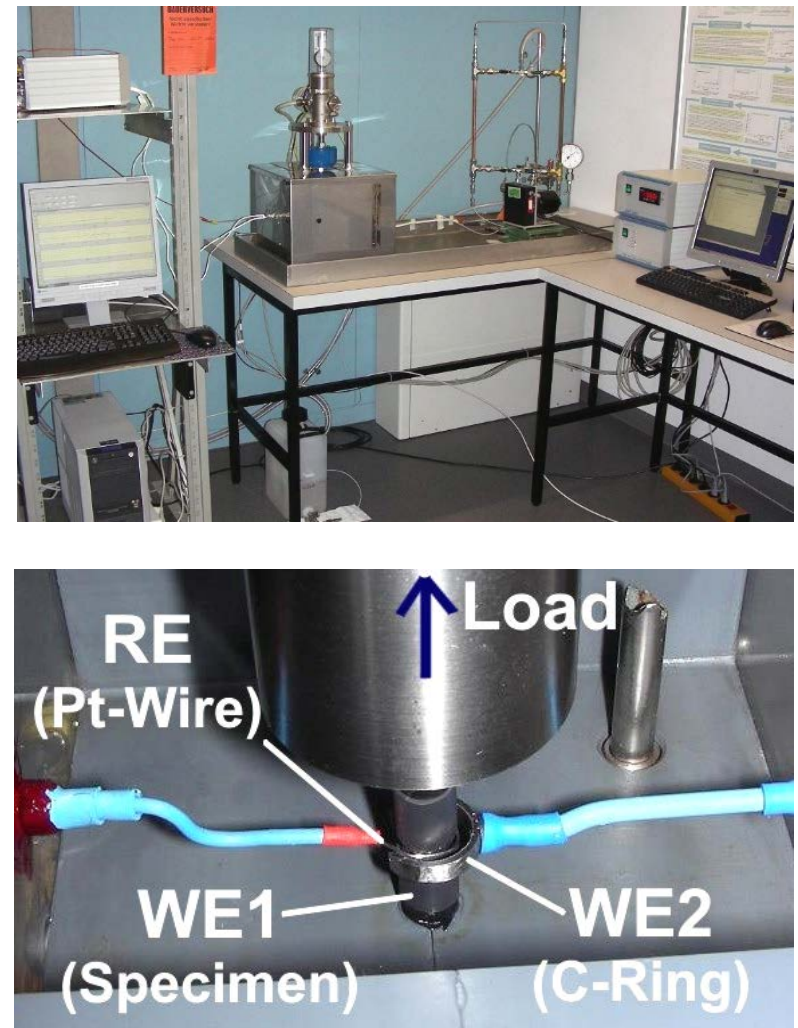

Figure 2: Schematic of the cell configuration and experimental setup for the EN measurements during CERT tests with round bar tensile specimens (a); photograph of the cell configuration and water loop with electromechanical tensile machine and EN measurement device (b). 

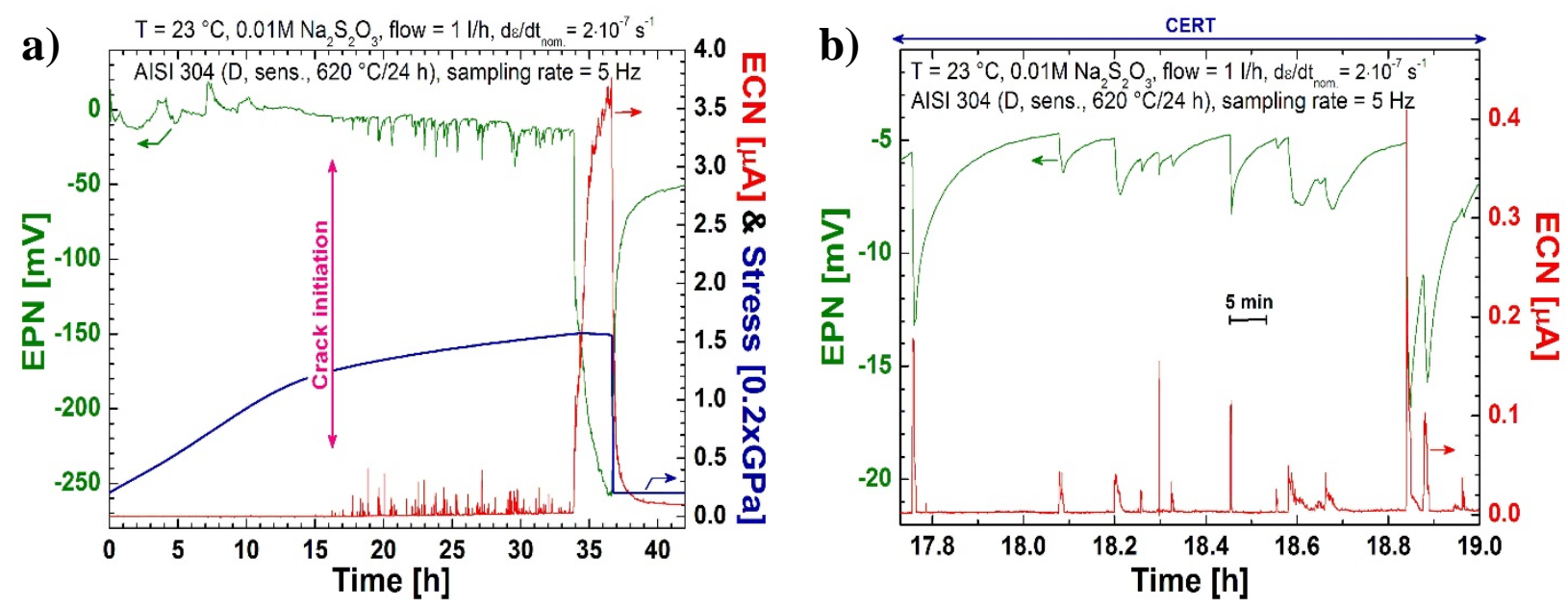

Figure 3: Typical current and potential transients and increase/decrease of the baseline ECN/EPN signal during a CERT test with sensitised stainless steel (“D”) in aqueous thiosulphate solution at room temperature (a); shape of individual transients from (a) at higher magnification (b).
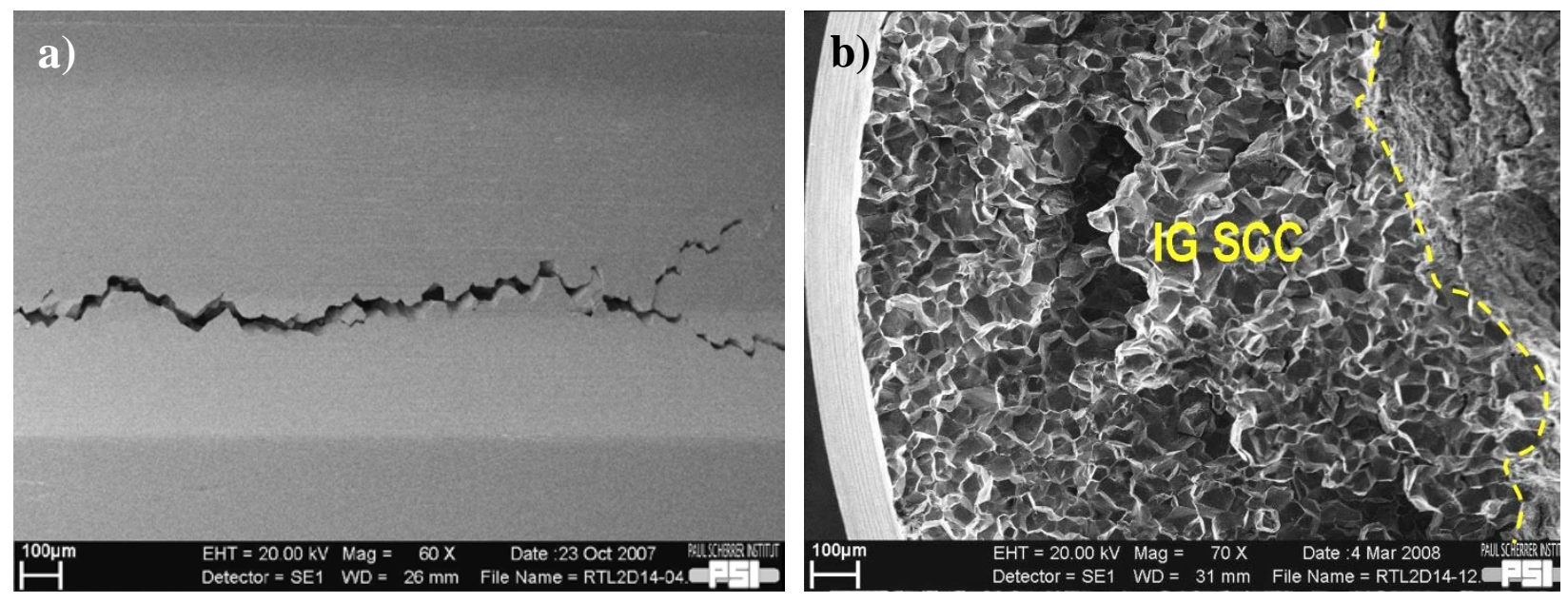

Figure 4: Post-test SEM examination of the specimen from the CERT test shown in Figure 3

revealed several branched IG SCC cracks in the notched area of the specimen (a); SEM micrograph of a crack flank after opening the specimen by mechanical overloading in air (b). 


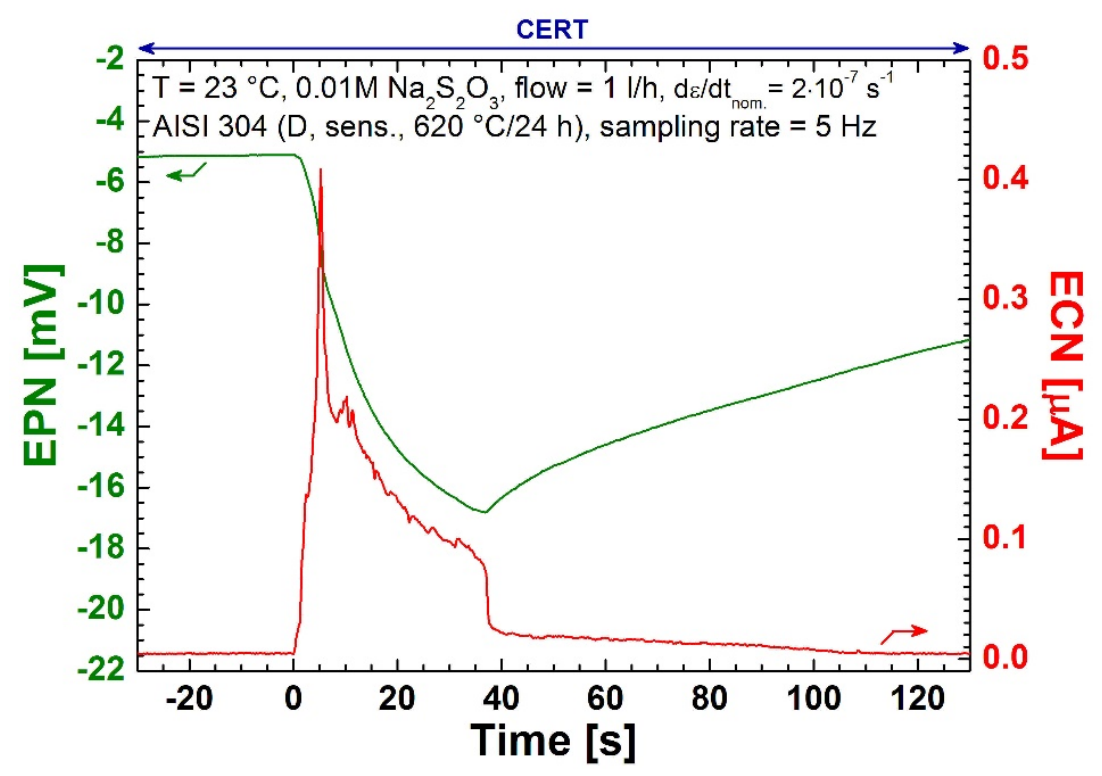

Figure 5: Typical shape of a single current and potential transient indicating one of the initial steps of SCC initiation during a CERT test with a heavily sensitised stainless steel (“D”) in aqueous thiosulphate solution.

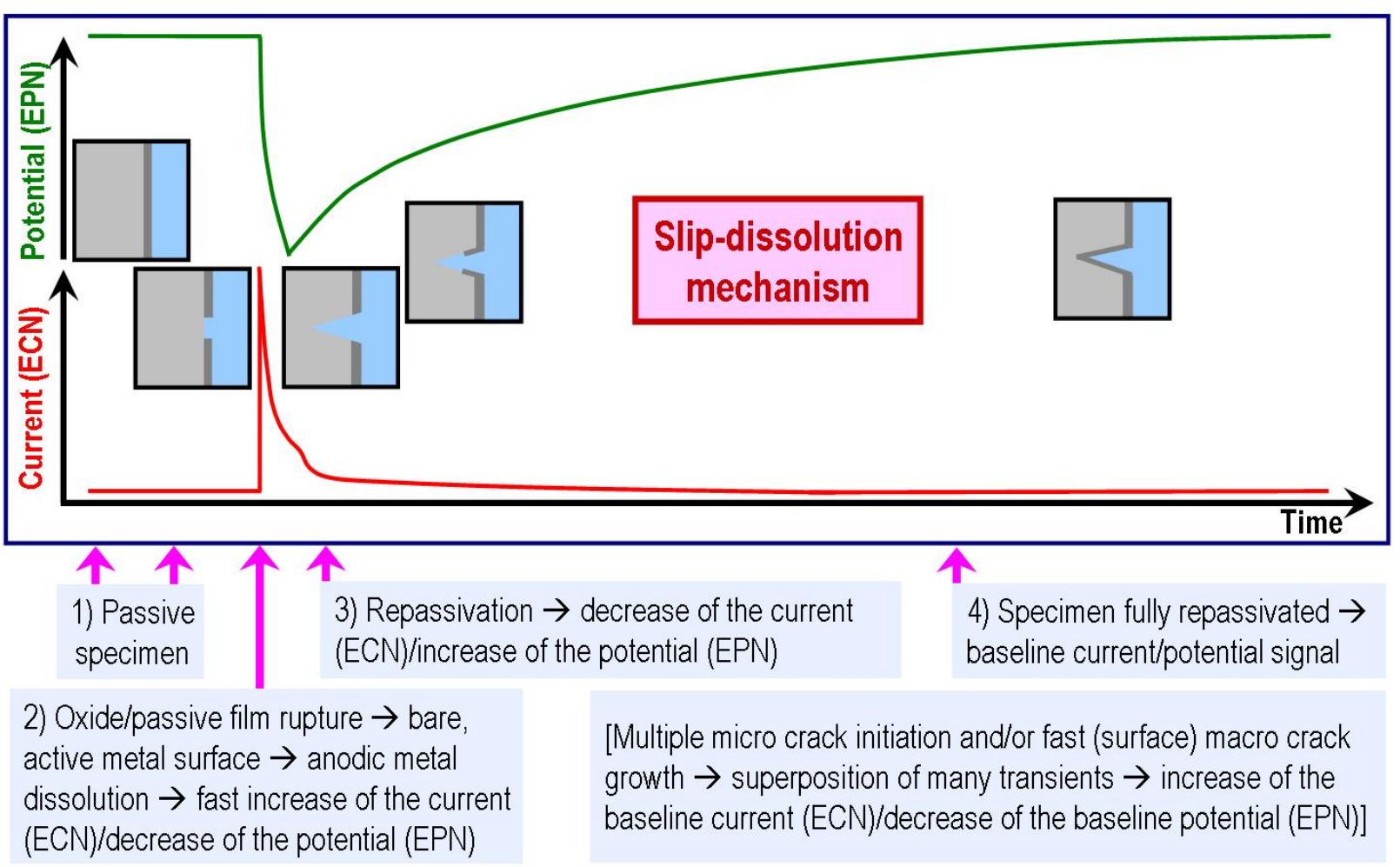

Figure 6: Schematic of typical current and potential noise transients of a crack initiation event, as observed during the experiments and according to the slip-dissolution mechanism [21, 22]. 

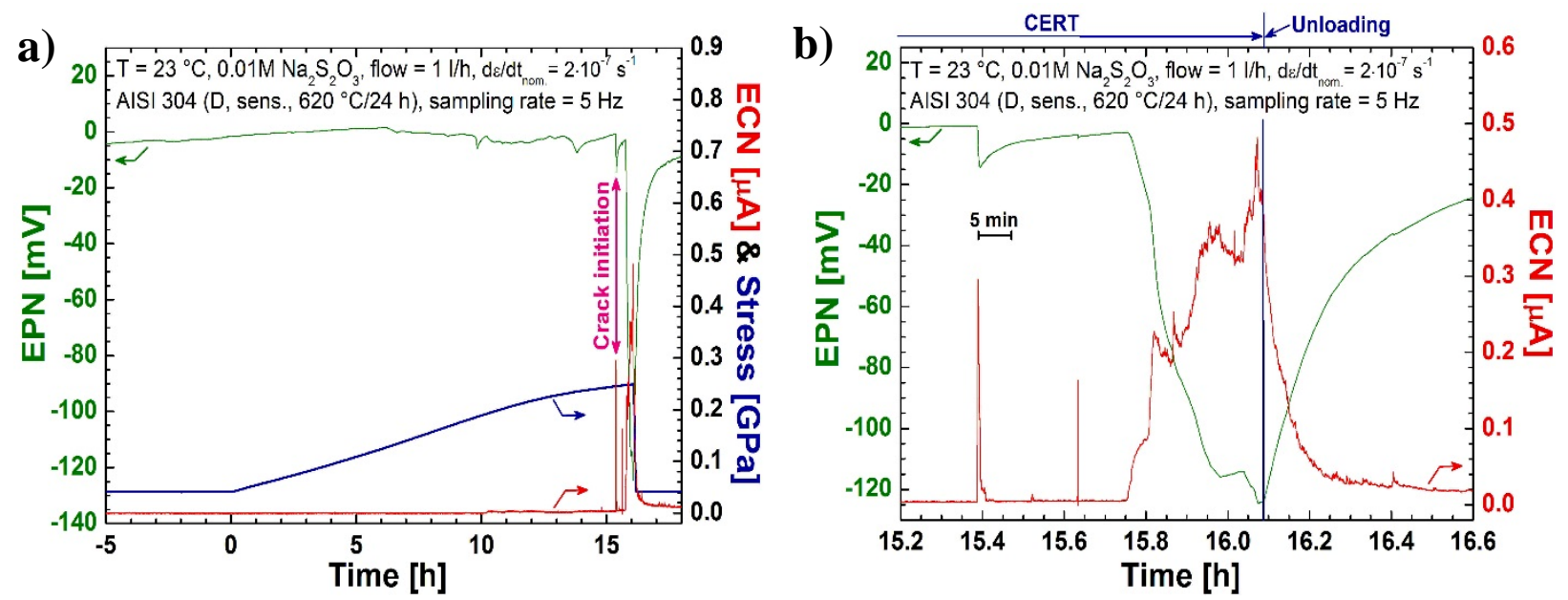

Figure 7: ECN and EPN signals of a CERT test with a sensitised stainless steel ("D”) in aqueous thiosulphate solution, which was interrupted after the first relevant transients appeared in the EN signal (a); higher magnification of the transients (b).

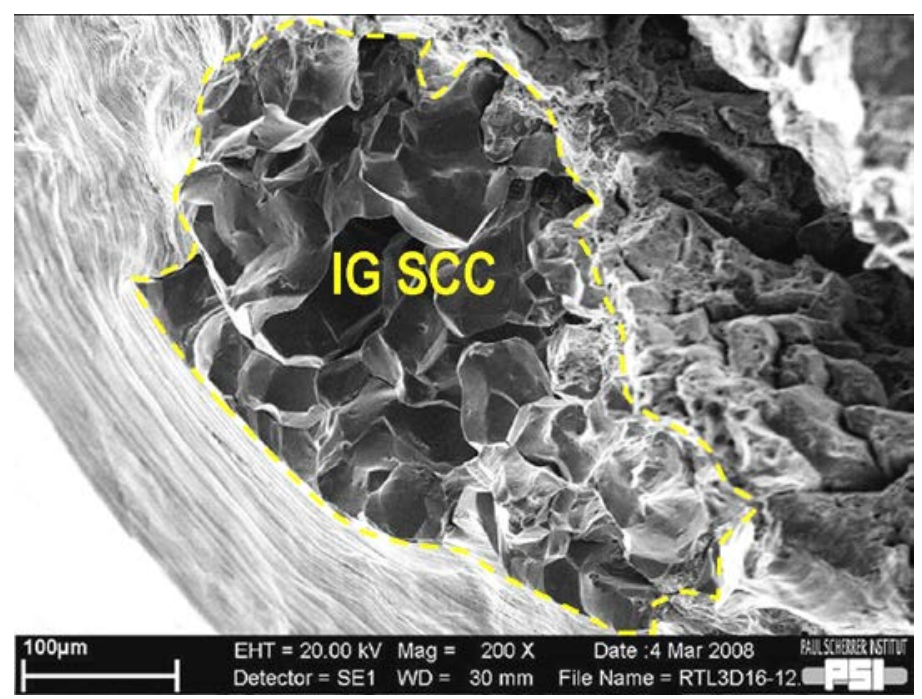

Figure 8: Post-test examination of the specimen from the CERT test shown in Figure 7 in the SEM revealed one IG SCC crack in the specimen; the current micrograph shows one crack flank after opening the specimen by mechanical overloading. 

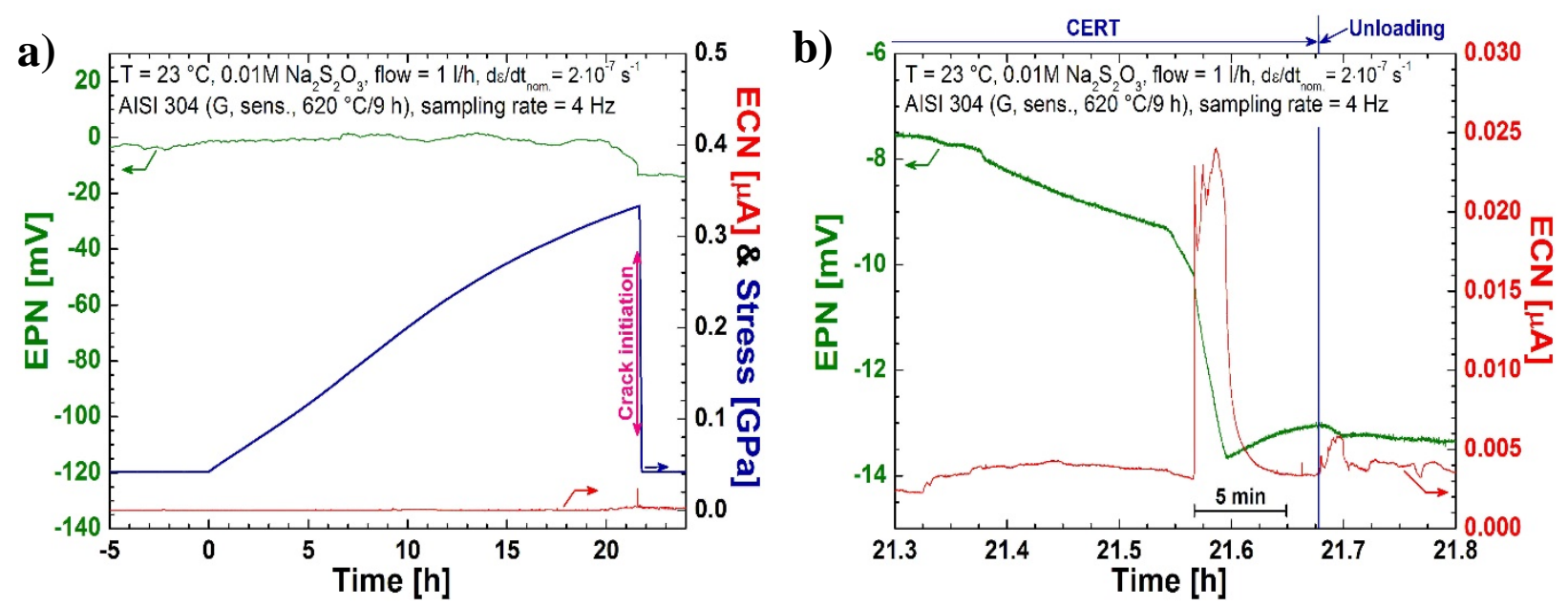

Figure 9: ECN and EPN signals of a CERT test with a sensitised stainless steel (“G”) in aqueous thiosulphate solution, which was interrupted after the first transient appeared in the EN signal (a); higher magnification of the transient (b).

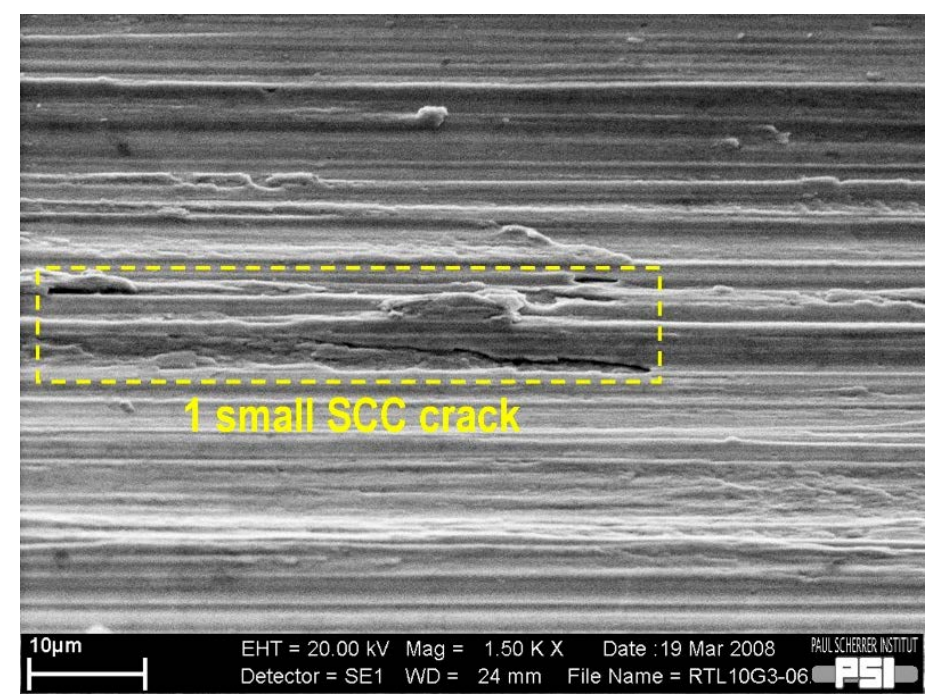

Figure 10: SEM post-test examination of the specimen from the CERT test shown in Figure 9 revealed only one small crack in the specimen. 


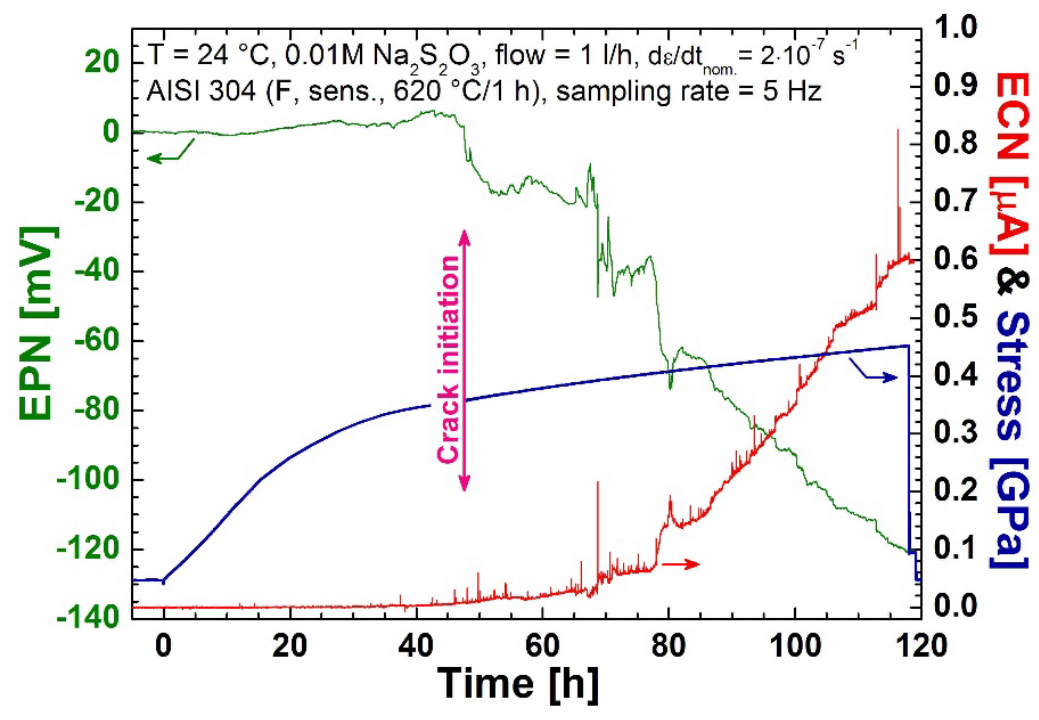

Figure 11: ECN and EPN signals during a CERT test with a slightly sensitised stainless steel ("F”) in aqueous thiosulphate solution; increase/decrease of the ECN/EPN baseline signal with small transients.
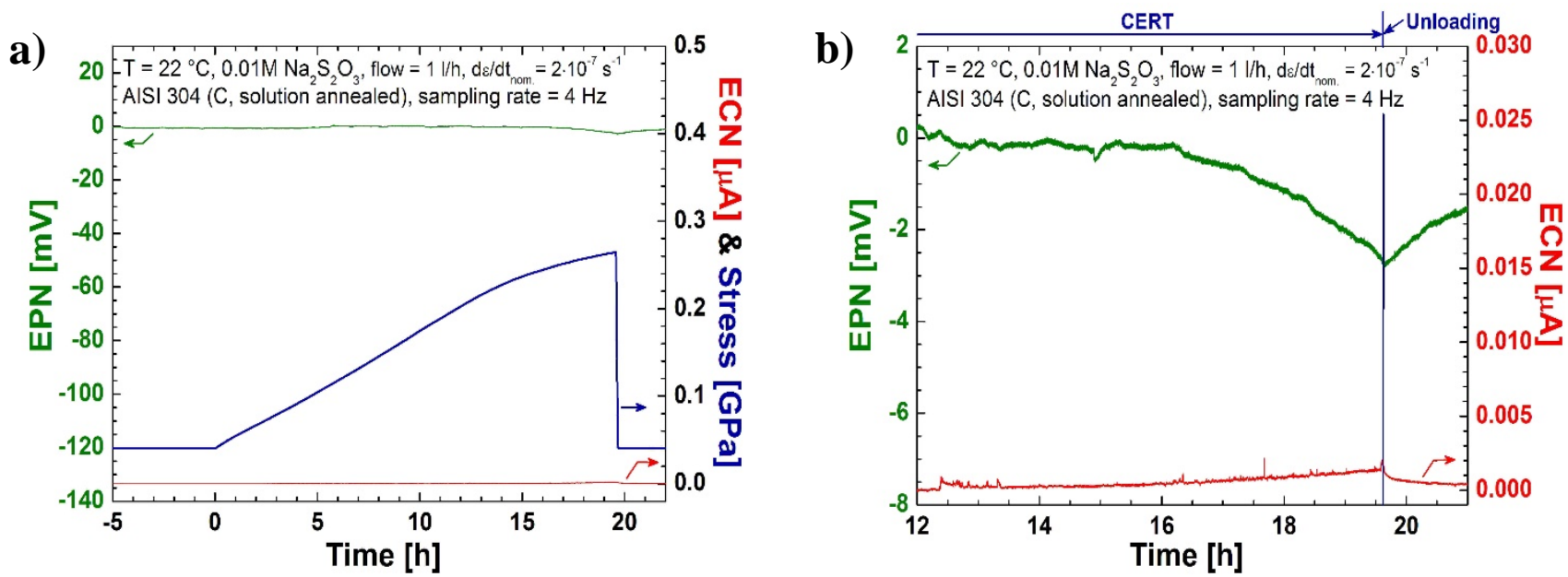

Figure 12: ECN and EPN signals during a CERT test with solution annealed stainless steel (“C”) in aqueous thiosulphate solution without cracking (a); higher magnification of the EN signals (b). 


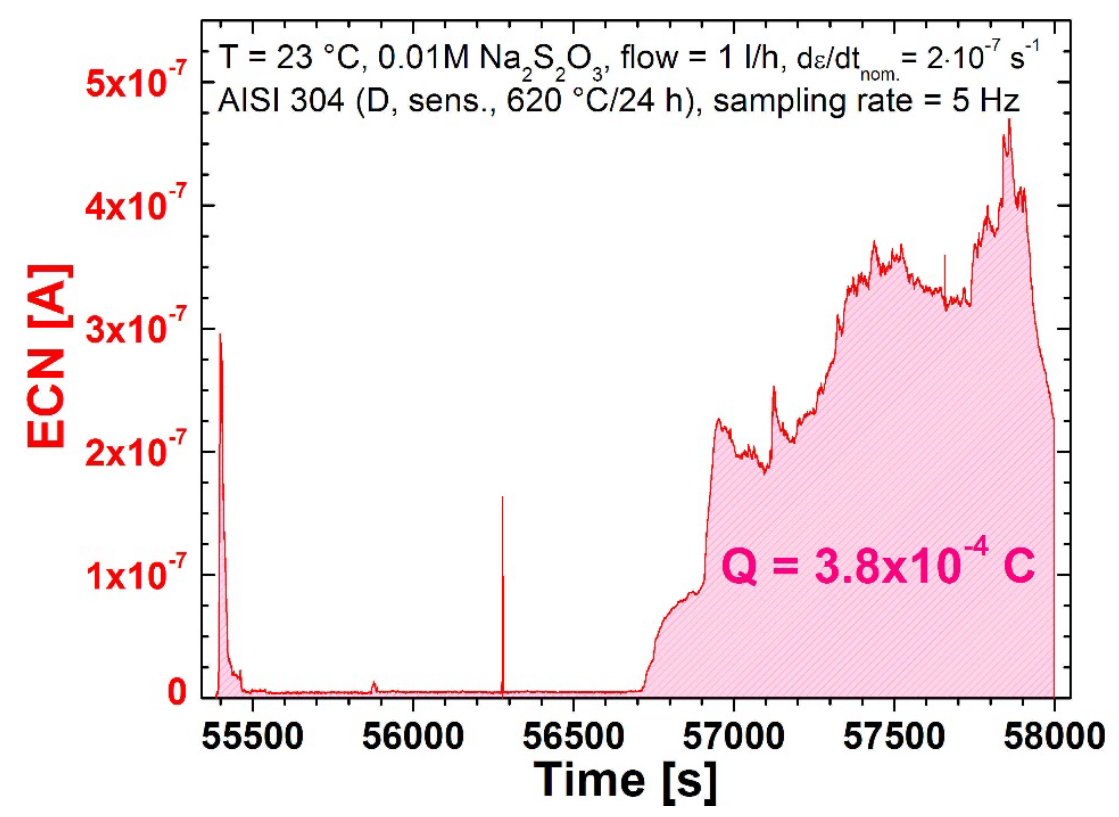

Figure 13: Estimation of the charge (Q) accumulated during SCC initiation in test 2 by integration of the current-time curve.

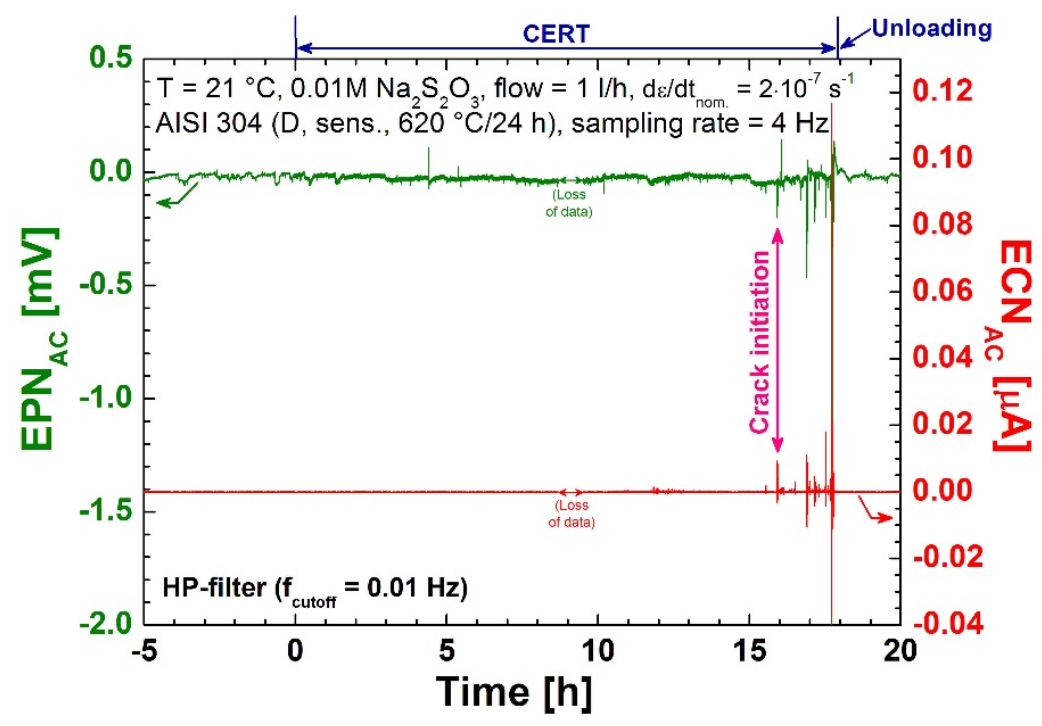

Figure 14: High-pass (HP) filtered ECN and EPN signals during a CERT test with sensitised stainless steel ("D”) in aqueous thiosulphate solution at room temperature. 